\title{
Socio-Demographic Profile and Prevalence of Tuberculosis (TB) Treatment Outcomes among Tuberculosis/Human Immunodeficiency Virus (TB/HIV) Co-Infected Patients in Kelantan
}

\author{
Siti Romaino Mohd Nor ${ }^{1,2}$, Mohd Rozi Husin³, Mat Zuki Mat Jaeb ${ }^{4}$ and \\ Nyi Nyi Naing* \\ ${ }^{1}$ Faculty of Medicine, Universiti Sultan Zainal Abidin, Medical Campus, Jalan Sultan Mahmud, 20400 UniSZA, \\ Kuala Terengganu, Terengganu, Malaysia \\ ${ }^{2}$ Clinical Research Centre Kelantan, Hospital Raja Perempuan Zainab II, 15586 Kota Bharu, \\ Kelantan, Malaysia \\ ${ }^{3}$ TB/Leprosy Sector, Jabatan Kesihatan Negeri Kelantan, 15200 Kota Bharu, Kelantan, Malaysia \\ ${ }^{4}$ Respiratory Unit, Department of Medicine, Hospital Raja Perempuan Zainab II, 15586 Kota Bharu, \\ Kelantan, Malaysia
}

\begin{abstract}
In Kelantan, the prevalence of Tuberculosis (TB) treatment success rate among TB/HIV co-infection is still below the success target of the World Health Organisation (WHO). Our objective was to assess the socio-demographic profile and determine the prevalence of TB treatment outcomes among TB/HIV co-infected patients in Kelantan. The crosssectional study involved secondary data from the MyTB online system from January 2014 to December 2018, carried out at TB/Leprosy Sector, State Health Department of Kelantan. The data were analysed using SPSS version 25.0 and STATA version 14. The ethics approval was obtained from the UniSZA Human Research Ethics Committee (UHREC) and Medical Research Ethics Committee (MREC) of Ministry of Health (MOH). There were 6,313 TB cases in Kelantan. Of these, 703 (11.1\%) cases were TB/HIV co-infection. However, 36 cases were excluded, and 667 cases were evaluated based on inclusion and exclusion

ARTICLE INFO

Article history:

Received: 04 November 2020

Accepted: 01 April 2021

Published: 22 September 2021

DOI: https://doi.org/10.47836/pjst.29.4.03

$\overline{\text { E-mail addresses: }}$

romainomn@gmail.com (Siti Romaino Mohd Nor)

mohdrozi@moh.gov.my (Mohd Rozi Husin)

matzu@gmail.com (Mat Zuki Mat Jaeb)

syedhatim@unisza.edu.my (Nyi Nyi Naing)

* Corresponding author criteria. The mean (SD) age was 38.7 (7.9) years, and the mean duration of TB treatment was 202.8 (131.27) days. The prevalence of successful treatment was $57.1 \%$, with $19.8 \%$ cases were cured, and another $37.3 \%$ cases were completed treatment. While the unsuccessful were $42.9 \%$, with $10.1 \%$ cases were defaulted, and $32.8 \%$ cases died. The
\end{abstract}


successful outcomes were significantly associated with the educational level, the anatomy of TB location, smoking status, DOTS by health care providers, source of notification, the place of treatment and method of detection. This study provides the basic data of patient's socio-demographic profiles, and the prevalence of TB treatment success in Kelantan is under international target by WHO of $\geq 90.0 \%$.

Keywords: Co-infected patients, Human Immunodeficiency Virus, HIV, prevalence, socio-demographic, Tuberculosis, TB

\section{INTRODUCTION}

Tuberculosis (TB) is an infectious disease that remains a primary global health concern. Worldwide, TB is known as the top 10 cause of death, and each year millions of people fall sick with TB. In 2017, a total of 6.7 million people with TB were notified and reported to World Health Organization (WHO) by National TB Programmes (NTPs). Of these, 6.4 million had reported as new or relapse TB cases. This number has been increasing since 2013. Among people living with Human Immunodeficiency Virus (PLHIV), there were 464,633 TB cases, with $84 \%$ were on Anti-Retroviral Therapy (ART). As a result, the number of TB deaths among PLHIV has decreased by 44\%, from 534000 in 2000 to 300 000 cases in 2017. At the same time, HIV-negative people decreased by $29 \%$, from 1.8 in 2000 to 1.3 million in 2017 (WHO, 2018a).

WHO recommends a Directly Observed Treatment Short-Course (DOTS) strategy to achieve a targeted cure rate. This strategy has shown improvement in the cure rate in many countries. TB treatment should be completed for six months, requires frequent clinic visits and monitoring, and may cause terrible experience side effects for the patients. It was challenging for patients to complete their TB treatment. However, the success rate of TB treatment in Malaysia is still below the Millennium Development Goal (MDG) target of $85 \%$ and much lower than the End TB Strategy success rate for 2025 of $90.0 \%$ (WHO, 2019).

To date, the treatment outcomes among TB patients with a range of success rates have been published in a few studies from different states of Malaysia. The success rate of TB treatment among TB/HIV co-infected patients is much lower than new TB patients in general ( $75 \%$ vs $83 \%$ ). It highlights the need to improve TB and HIV services to save TB/HIV co-infected patients ( WHO, 2018b). In the state of Kelantan alone, the treatment success rate in 2017 was only $27.9 \%$ (Jalal et al., 2017). Based on this, the method for improvement was needed, particularly in achieving a better cure rate.

The Regional Strategic Plan towards Ending TB has been implemented to achieve successful TB elimination by 2035. Therefore, TB and HIV programmes need to be strengthened by understanding the socio-demographic characteristics, and clinical 
characteristics that may contribute to and affect the outcome of TB treatment. Many factors have affected poor treatment outcomes and treatment effectiveness, including demanding access to treatment, poor use of DOTS, poor communication between patients and health care providers, lack of incentives, lack of active search for lost patients, and limitations of supervision (Hannah et al., 2017; Liu et al., 2018; \& Wen et al., 2018). In this regard, this study was conducted to assess the socio-demographic profile and determine the prevalence of TB treatment outcomes among TB/HIV co-infected patients in Kelantan.

\section{MATERIALS AND METHODS}

\section{Study Design}

The cross-sectional study involved the secondary data from MyTB online system. The population in this study consisted of all TB/HIV co-infected patients in Kelantan on January 2014 to December 2018. The selection of these subgroups of patients was based on the recommendation by WHO to evaluate patients separately for assessing the NTPs performance (Ministry of Health Malaysia, 2016). This study was conducted at State TB organiser, TB/Leprosy Sector, State Health Department of Kelantan (JKNK), Malaysia responsible for managing the MyTB online system registry.

\section{Sample Size Determination and Sampling Method}

All TB/HIV co-infected patients registered for TB treatment during the study period and fulfilled the inclusion and exclusion criteria. The single proportion formula $n=(Z / \Delta)^{2}$ $\mathrm{P}(1-\mathrm{P}) ; \mathrm{n}=$ Minimum required sample size, $\mathrm{Z}=$ Value of standard normal distribution was $1.96, \Delta=$ Precision of $0.05, \mathrm{P}=$ proportion of success (27.9\%) (Jalal et al., 2017). The minimum required sample size for the estimated proportion of successful treatment with a $95 \%$ confidence interval (CI) within a 5\% point estimate was 309 patients. Assuming $15 \%$ of dropout, the number of the sample size needed was 364 patients. No probability sampling method was applied.

\section{Study Procedure}

The person in charge at TB/Leprosy Sector has retrieved and downloaded the data, including patient's socio-demographic characteristics, clinical characteristics and TB treatment outcome from MyTB online system into Microsoft Excel for patients identified as TB/HIV co-infection. However, the marital status was only recorded in TBIS 10A-1 Form but was unavailable in the MyTB online system. In addition, the data were not fully recorded for monthly income, with many missing data $(91.0 \%)$. Therefore, these two parameters were not reported. All the information needed in this study was extracted in December 2019. 


\section{Operational Definitions}

According to the Clinical Practice Guidelines for Management of Tuberculosis by the Ministry of Health, Malaysia (2012), the following TB treatment outcome operational terms were used in this study:

1. Cured: Former smear-positive patient was cured in the last month of treatment and at least one previous occasion.

2. Completed treatment: A patient who has completed treatment has not meet the criteria for being classified as a cure or failure

3. Treatment failed: A patient whose sputum was smear-positive at five months or later during treatment.

4. Died: A patient who died for any reason during treatment.

5. Default: A patient who has interrupted treatment for two consecutive months or more.

In this analysis, treatment success outcome was defined as the sum of cured patients and those who completed treatment. In contrast, all the other outcomes (treatment failed, died, default) were considered unsuccessful.

Chest X-ray presentation upon diagnosis was categorised according to how severe the lesion appeared on the X-ray film. It was categorised into the followings:

1. No lesion if chest X-ray showed no lesions,

2. Minimal if chest $\mathrm{X}$-ray showed a few lesions,

3. Moderate advance if chest X-ray showed many lesions,

4. Far advance if chest X-ray showed extensive lesions or miliary appearance, and

5. Not performed if chest X-ray was not done during the diagnosis

\section{Inclusion and Exclusion Criteria}

The inclusion criteria were TB and HIV patients aged $\geq 18$ years old, tested positive for TB and HIV and confirmed TB. At the same time, the exclusion criteria were patients transferred to other treatment centres or who were still on TB treatment during the data collection (December 2019) because their treatment outcomes could not be determined. In addition, patients whose diagnoses were changed were also excluded because they were later discovered to have a different diagnosis.

\section{Ethical Consideration}

This study obtained ethics approval from the UniSZA Human Research Ethics Committee (UHREC) (UniSZA.C/2/UHREC/628-2 Jld 2 (20)) and Medical Research Ethics Committee (MREC) of MOH (NMRR-18-3464-42863). Privacy and confidentiality of patients were maintained by anonymising their identities. 


\section{Statistical Analysis}

Data were analysed using IBM SPSS Statistics version 25.0 and STATA 14. The data were explored, checked and cleaned to detect any missing value or error. The categorical variables were summarized in frequency (n) and percentage (\%). At the same time, the numerical variables were described in mean and standard deviation (SD) or median and interquartile range (IQR) depending on the normality of distribution. Prevalence was presented with percentage (\%) with corresponding 95\% CI. Inferential statistics were performed using either Pearson Chi-square or Fisher's exact test. The level of significant alpha was set at 0.05 .

\section{RESULTS}

A total of 6,313 TB cases in Kelantan were registered in MyTB online system from January 2014 to December 2018. Of these, 703 (11.1\%) cases were TB/HIV co-infection. However, 36 cases were excluded due to transfer out (3), change of diagnosis (24) and still ongoing treatment (9). Therefore, 667 cases were evaluated in this study based on inclusion criteria (Figure 1). Of these 667 cases, their ages ranged between 18 and 77 years, with a mean (SD) of 38.7 (7.9) years. While the range of the duration of TB treatment was 0 to 722 days, with a mean (SD) were 202.8 (131.27) days.

The majority of cases were male (88.5\%), Malays (96.7\%), with secondary level education $(80.2 \%)$, living in the rural area $(77.1 \%)$, unemployed $(44.7 \%)$, have BCG scar $(94.9 \%)$, new cases $(82.8 \%)$, smoking $(66.0 \%)$, under DOTS by health care providers $(85.9 \%)$, received treatment from public hospitals $(81.1 \%)$ and passive method detection (85.5\%) (Figure 2). Only $3.1 \%$ of patients had diabetes, $1.3 \%$ given 2 SHRZ and $5.5 \%$ under HAART treatment (Table 1).

In terms of the anatomy of TB location, there were 428 (64.2\%) who had Pulmonary TB, 164 (24.6\%) had Extra-Pulmonary TB, and 75 (11.2\%) had both Pulmonary TB and Extra-Pulmonary TB. Meanwhile, chest X-ray results which are examined in Pulmonary TB and Extra-Pulmonary TB, showed there were 94 (14.1\%) no lesion, 387 (58.0\%) minimal, $171(25.6 \%)$ moderate advance, $5(0.7 \%)$ far advance and $10(1.5 \%)$ not performed the diagnosis. From ten districts in Kelantan, the majority of them were from Kota Bharu $(38.5 \%)$.

In this study, the prevalence of successful TB treatment among TB/HIV co-infected patients was $57.1 \%$. The successful outcomes were achieved in 381 cases, with $132(19.8 \%)$ cases cured and another $249(37.3 \%)$ cases where treatment was completed. While the unsuccessful treatment outcomes were $42.9 \%$ achieved in 286 cases, with $67(10.1 \%)$ cases were defaulted and $219(32.8 \%)$ were cases of death. There were no treatment failure cases identified (Table 2). 
The proportion of patients with successful outcomes in this study was significantly associated with level of education $(P=0.018)$, anatomy of TB location $(P=0.015)$, smoking status $(P=0.004)$, DOTS by health care providers $(P=<0.001)$, source of notification $(P=$ $<0.001)$, place of treatment $(P=<0.001)$ and method of detection $(P=0.043)$. However, other socio-demographics and clinical characteristics were not significantly associated with treatment outcomes. Table 1 summarizes the socio-demographic characteristics and other related factors among all study subjects.

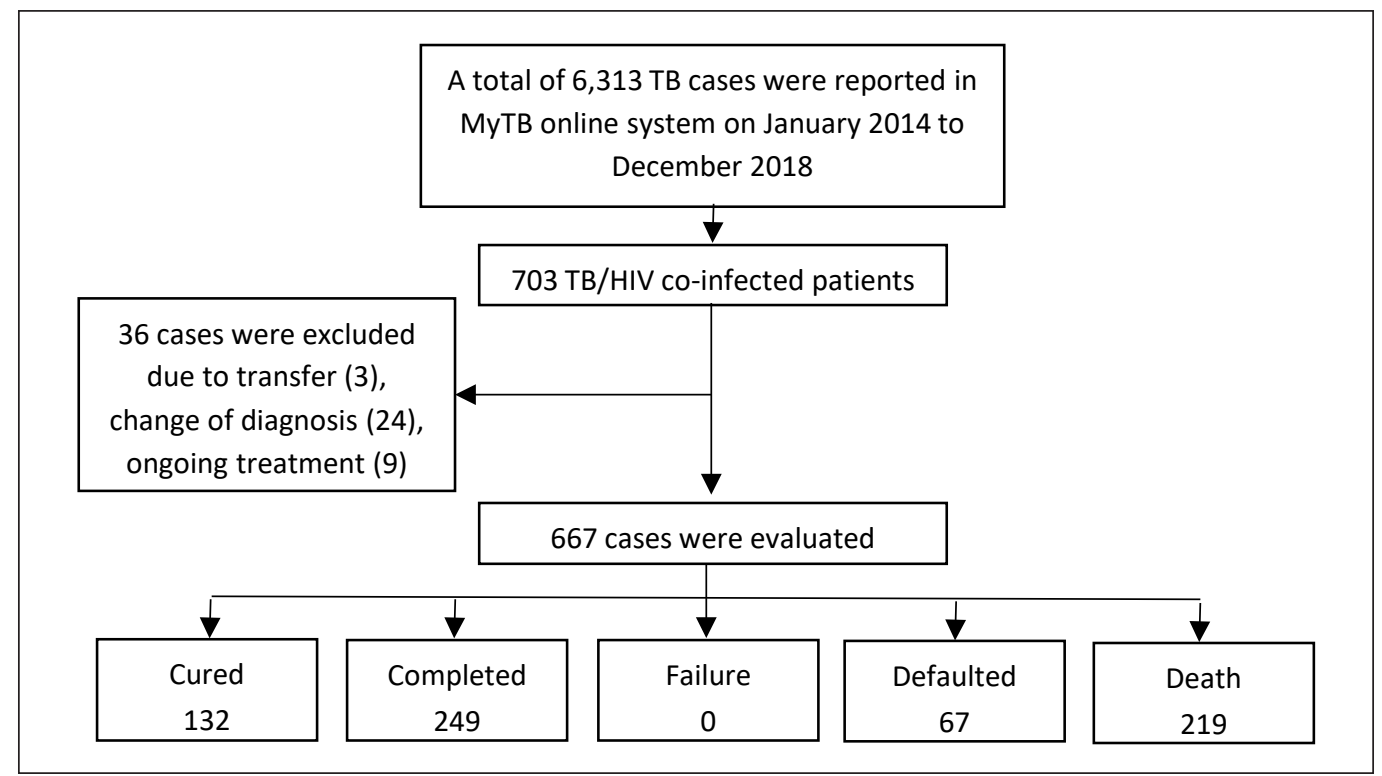

Figure 1. A schematic diagram for the selection of patients included

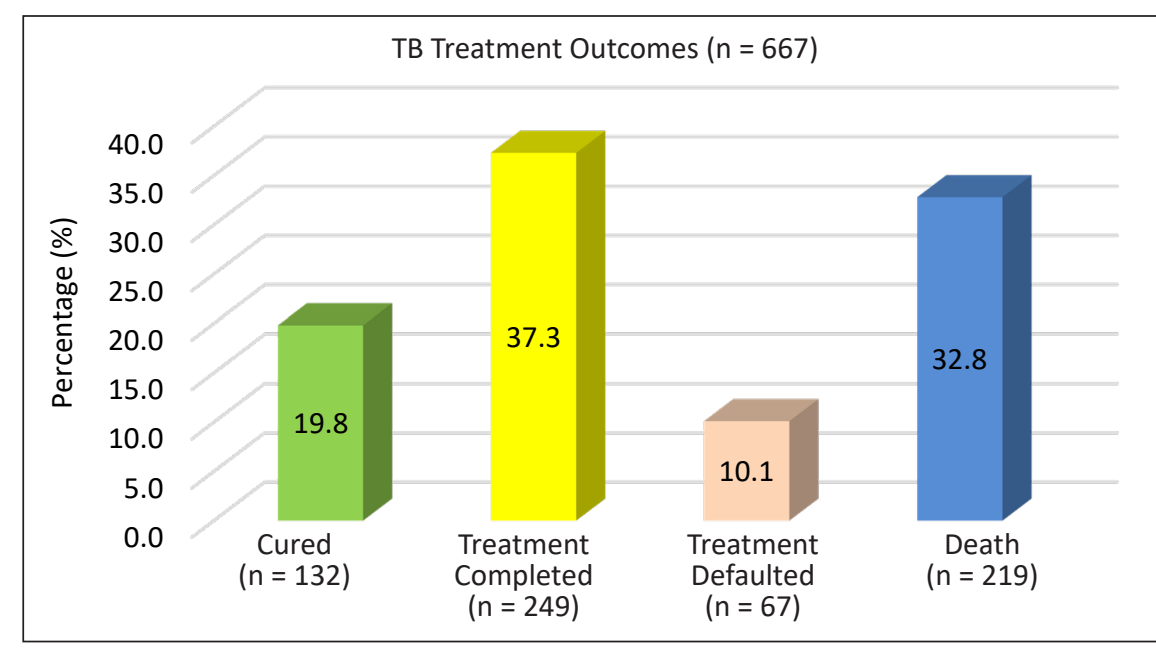

Figure 2. TB treatment outcomes among 667 TB/HIV co-infected patients in Kelantan in 2014 to 2018 
Table 1

Socio-demographic and clinical characteristics among all study subjects $(n=667)$

\begin{tabular}{|c|c|c|c|c|c|}
\hline & & \multicolumn{2}{|c|}{ Treatment Outcome n (\%) } & \multirow[b]{2}{*}{$\chi^{2}(\mathrm{df})$} & \multirow[b]{2}{*}{$P$ value } \\
\hline & & $\begin{array}{l}\text { Unsuccessful } \\
286(42.9 \%)\end{array}$ & $\begin{array}{c}\text { Successful } \\
381(57.1 \%)\end{array}$ & & \\
\hline \multirow[t]{2}{*}{ Gender } & Male & $256(43.4)$ & $334(56.6)$ & $0.545(1)$ & $0.460^{\mathrm{a}}$ \\
\hline & Female & $30(39.0)$ & $47(61.0)$ & & \\
\hline \multirow[t]{2}{*}{ Race } & Malays & $276(42.8)$ & $369(57.2)$ & $0.062(1)$ & $0.804^{\mathrm{a}}$ \\
\hline & Non-Malays & $10(45.5)$ & $12(54.5)$ & & \\
\hline \multirow{4}{*}{$\begin{array}{l}\text { Level of } \\
\text { education }\end{array}$} & No education & $6(50.0)$ & $6(50.0)$ & 10.079 & $0.018^{\mathrm{a}}$ \\
\hline & Primary school & $29(39.2)$ & $45(60.8)$ & (3) & \\
\hline & Secondary school & $241(45.0)$ & $294(55.0)$ & & \\
\hline & Tertiary level & $10(21.7)$ & $36(78.3)$ & & \\
\hline \multirow[t]{2}{*}{ Residency } & Urban & $65(42.5)$ & $88(57.5)$ & $0.013(1)$ & $0.910^{\mathrm{a}}$ \\
\hline & Rural & $221(43.0)$ & $293(57.0)$ & & \\
\hline \multirow[t]{5}{*}{ Occupation } & Government servant & $7(25.0)$ & $21(75.0)$ & $8.824(4)$ & $0.066^{\mathrm{a}}$ \\
\hline & Own business & $38(47.5)$ & $42(52.5)$ & & \\
\hline & Unemployed & $132(44.3)$ & $166(55.7)$ & & \\
\hline & Prisoner & $24(32.0)$ & $51(68.0)$ & & \\
\hline & Others & $85(45.7)$ & $101(54.3)$ & & \\
\hline \multirow[t]{2}{*}{ Diabetes mellitus } & No & $279(43.2)$ & $367(56.8)$ & $0.807(1)$ & $0.369^{\mathrm{a}}$ \\
\hline & Yes & $7(33.3)$ & $14(66.7)$ & & \\
\hline \multirow[t]{2}{*}{ BCG scar } & No & $13(38.2)$ & $21(61.8)$ & $0.315(1)$ & $0.574^{\mathrm{a}}$ \\
\hline & Yes & $273(43.1)$ & $360(56.9)$ & & \\
\hline \multirow[t]{2}{*}{ HIV positive } & Screening & $270(43.2)$ & $355(56.8)$ & $0.419(1)$ & $0.518^{\mathrm{a}}$ \\
\hline & Verification & $16(38.1)$ & $26(61.9)$ & & \\
\hline \multirow{3}{*}{$\begin{array}{l}\text { Anatomy of TB } \\
\text { location }\end{array}$} & Extra-pulmonary & $76(46.3)$ & $88(53.7)$ & $8.373(2)$ & $0.015^{\mathrm{a}}$ \\
\hline & Pulmonary & $168(39.3)$ & $260(60.7)$ & & \\
\hline & $\begin{array}{l}\text { Extra-pulmonary \& } \\
\text { pulmonary }\end{array}$ & $42(56.0)$ & $33(44.0)$ & & \\
\hline \multirow{5}{*}{$\begin{array}{l}\text { Chest X-ray } \\
\text { status during } \\
\text { diagnose }\end{array}$} & No Lesion & $37(39.4)$ & $57(60.6)$ & & $0.052^{b}$ \\
\hline & Minimal & $154(39.8)$ & $233(60.2)$ & & \\
\hline & Moderately advanced & $87(50.9)$ & $84(49.1)$ & & \\
\hline & Far advanced & $4(80.0)$ & $1(20.0)$ & & \\
\hline & Not performed & $4(40.0)$ & $6(60.0)$ & & \\
\hline \multirow{3}{*}{$\begin{array}{l}\text { Case TB } \\
\text { category }\end{array}$} & New case & $232(42.0)$ & $320(58.0)$ & $0.988(2)$ & $0.610^{\mathrm{a}}$ \\
\hline & Relapse case & $38(46.3)$ & $44(53.7)$ & & \\
\hline & Case after treatment default & $16(48.5)$ & $17(51.5)$ & & \\
\hline \multirow[t]{2}{*}{ Smoking status } & No & $80(35.2)$ & $147(64.8)$ & $8.193(1)$ & $0.004^{\mathrm{a}}$ \\
\hline & Yes & $206(46.8)$ & $234(53.2)$ & & \\
\hline \multirow{4}{*}{$\begin{array}{l}\text { Regime of } \\
\text { treatment }\end{array}$} & 2SHRZ & $7(77.8)$ & $2(22.2)$ & & $0.056^{\mathrm{b}}$ \\
\hline & 2EHRZ & $125(45.3)$ & $151(54.7)$ & & \\
\hline & $2 \mathrm{HRZ}$ & $2(66.7)$ & $1(33.3)$ & & \\
\hline & Others & $152(40.1)$ & $227(59.9)$ & & \\
\hline
\end{tabular}


Table 1 (continue)

\begin{tabular}{|c|c|c|c|c|c|}
\hline & & \multicolumn{2}{|c|}{ Treatment Outcome n (\%) } & \multirow[b]{2}{*}{$\chi^{2}(\mathrm{df})$} & \multirow[b]{2}{*}{$P$ value } \\
\hline & & $\begin{array}{l}\text { Unsuccessful } \\
286(42.9 \%)\end{array}$ & $\begin{array}{c}\text { Successful } \\
381(57.1 \%)\end{array}$ & & \\
\hline \multirow{2}{*}{$\begin{array}{l}\text { DOTs by Health } \\
\text { care providers }\end{array}$} & No & $77(98.7)$ & $1(1.3)$ & 119.631 & $<0.001^{\text {a }}$ \\
\hline & Yes & $193(33.7)$ & $380(66.3)$ & $(1)$ & \\
\hline \multirow{2}{*}{$\begin{array}{l}\text { HAART } \\
\text { treatment }\end{array}$} & No & $259(44.0)$ & $329(56.0)$ & $2.908(1)$ & $0.088^{\mathrm{a}}$ \\
\hline & Yes & $11(29.7)$ & $26(70.3)$ & & \\
\hline \multirow{2}{*}{$\begin{array}{l}\text { Source of } \\
\text { notification }\end{array}$} & Public hospital & $253(46.4)$ & $292(53.6)$ & 15.673 & $<0.001^{\mathrm{a}}$ \\
\hline & Public health clinic & $32(26.7)$ & $88(73.3)$ & (1) & \\
\hline \multirow{3}{*}{$\begin{array}{l}\text { Place of } \\
\text { treatment }\end{array}$} & Public hospital & $249(46.0)$ & $292(54.0)$ & & $<0.001^{b}$ \\
\hline & Public health clinic & $35(28.5)$ & $88(71.5)$ & & \\
\hline & Private health sector & $2(66.7)$ & $1(33.3)$ & & \\
\hline \multirow{3}{*}{$\begin{array}{l}\text { Method of } \\
\text { detection }\end{array}$} & Active & $15(51.7)$ & $14(48.3)$ & $6.273(2)$ & $0.043^{\mathrm{a}}$ \\
\hline & Passive & $251(44.0)$ & $319(56.0)$ & & \\
\hline & Screening & $20(29.4)$ & $48(70.6)$ & & \\
\hline \multirow[t]{10}{*}{ District } & Kota Bharu & $105(40.90)$ & $152(59.1)$ & $9.543(9)$ & $0.389^{\mathrm{a}}$ \\
\hline & Pasir Mas & $22(42.3)$ & $30(57.7)$ & & \\
\hline & Pasir Puteh & $20(47.6)$ & $22(52.4)$ & & \\
\hline & Tumpat & $34(43.0)$ & $45(57.0)$ & & \\
\hline & Bachok & $20(36.4)$ & $35(63.6)$ & & \\
\hline & Jeli & $15(55.6)$ & $12(44.4)$ & & \\
\hline & Kuala Krai & $21(55.3)$ & $17(44.7)$ & & \\
\hline & Machang & $18(36.0)$ & $32(64.0)$ & & \\
\hline & Tanah Merah & $25(52.1)$ & $23(47.9)$ & & \\
\hline & Gua Musang & $6(31.6)$ & $13(68.4)$ & & \\
\hline
\end{tabular}

a Pearson $\chi^{2}$ was applied using SPSS version 25.0

${ }^{\mathrm{b}}$ Fisher's Exact Test was applied using STATA 14

The source of the notification included case from the district office $(n=1)$ and case from private health sector $(n=1)$. These two variables were excluded because of the small sample size.

Table 2

The prevalence of TB treatment outcomes among all study participants $(n=667)$

\begin{tabular}{llcc}
\hline Treatment outcome & Categories & n & Percentage (95\% CI) \\
\hline \multirow{3}{*}{ Successful } & Cured & 132 & $19.8(16.78,22.82)$ \\
& Treatment Completed & 249 & $37.3(33.63,40.97)$ \\
\cline { 2 - 4 } & Total & 381 & $57.1(53.34,60.86)$ \\
\hline \multirow{3}{*}{ Unsuccessful } & Treatment Failure & 0 & $0(0,0)$ \\
& Treatment Defaulted & 67 & $10.1(7.83,12.37)$ \\
& Death & 219 & $32.8(30.98,34.62)$ \\
\cline { 2 - 4 } & Total & 286 & $42.9(39.14,46.66)$ \\
\hline
\end{tabular}




\section{DISCUSSION}

This study included a total of 667 cases, which were 381 successful and 286 unsuccessful TB treatment outcomes among TB/HIV co-infected patients. Unfortunately, published data on the treatment outcomes among TB/HIV co-infected patients in Kelantan were minimal. Therefore, the present study was designed to assess the socio-demographic profile and determine the prevalence of TB treatment outcomes among these high-risk groups in Kelantan. The results revealed significant differences in educational level, anatomy of TB location, smoking status, DOTS by health care providers, source of notification, and place of treatment. In addition, the method of detection was potentially associated with poor treatment outcomes in this study. However, other variables were not significantly associated with treatment outcomes.

The socio-demographic results in this study were similar to the results reported in the study among Pulmonary TB in Kelantan in 2011 in terms of gender, race, occupation status and smoking status, but contradict in terms of residency and death rate (Ronaidi et al., 2011). Among these 667 cases, $82.8 \%$ new TB cases were reported, which was similar to that observed in 2010 to 2012 among TB/HIV co-infected patients in Southwest Ethiopia (85.2\%) (Abrha et al., 2015) and among TB/HIV co-infected patients in rural South Africa (84.9\%) (Jacobson et al., 2015). However, it was lower compared to the study among Pulmonary Tuberculosis in Kelantan (90.0\%) (Ronaidi et al., 2011) and the study among TB patients in Malaysian National TB Surveillance Database in 2012 (93.6\%) (Liew et al., 2015).

The death rate in the present study was $32.8 \%$, lower than reported in 2015 among TB patients (46.0\%) (Liew et al., 2015), but higher than reported in 2015 among HIV coinfected patients at Mizan-Aman General Hospital, Southwest Ethiopia (5.5\%) (Fiseha et al., 2015) and the study in 2020 among TB patients in Malaysia from 2014 to 2017 $(10.2 \%)$ (Tok et al., 2020). Based on data from the MyTB online system, the number of TB deaths in this study was identified as; confirmed cases of death by TB and advanced HIV (24 cases), cases of death not caused by TB but caused by other factors such as delay in diagnosis, failure of multiple systems, mismanagement, opportunistic infections and others (136 cases), and cases have not identified the cause of death (59 cases). Hence, strengthening surveillance, supervision and health education to reduce death should be prioritised in healthcare systems. In addition, although efforts have been initiated for a high-risk group with the goal of early detection and prevention of TB complications (Liew et al., 2015), the impact of these efforts has not yet been seen in this study.

The previous studies reported prevalence of TB/HIV co-infection varied according to different study sites and study populations. This study has shown that $11.1 \%$ of patients having a TB/HIV co-infection. It was equivalent to the prevalence in Malaysia of HIV in new cases of TB (12.6\%) in 2005 (WHO, 2008) and to the prevalence among TB patients 
in Klang Valley, Malaysia in 2010 (11.8\%) (Ismail \& Bulgiba, 2013). However, it was higher than reported from 2014 to 2017 in Malaysia (6.0\%) (Tok et al., 2020), from MOH in 2015 (5.9\%) (Ministry of Health, 2015), and Maharashtra in 2017 (7.28\%) (Warkari et al., 2017). However, this prevalence of TB/HIV co-infection in this study was lower than reported in Nigerian State of 20.5\% (Oshi et al., 2014), Lagos Nigeria of 21.6\% (Adejumo et al., 2017), Northern Ethiopia of 24.3\% (Mekonnen et al., 2015), Ethiopia of 29.4\% (Ali et al., 2016) and Malawi of 56.0\% (Tweya et al., 2013).

Analysis of the study data demonstrated that the TB/HIV co-infected patients had poor treatment outcomes with a success rate of only $57.1 \%$, which is lower than the WHO target set for MDG (85\%) and far lower to End TB Strategy success rate for 2025 $(\geq 90.0 \%)$ (WHO, 2019). These results are almost similar to the study of 26,168 TB cases notified in Malaysia in 2017, 56.0\% (WHO, 2018a), TB/HIV co-infected patients in the Klang Valley, 53.4\% (Ismail \& Bulgiba, 2013) and of TB patients enrolled at Nekemte Specialized Hospital, Western Ethiopia, 58.06\% (Fekadu et al., 2020).

The success rate in this study was lower than in Malaysia from 2014 to $2017(80.7 \%)$ (Tok et al., 2020), Ethiopia (88.2\%) (Ali et al., 2016), North West Ethiopia (77.3\%) (Sinshaw et al., 2017), South-East Nigeria (81.4\%) (Duru et al., 2016), Western Ethiopia (60.7\%) (Eyasu et al., 2014), and Northern Ethiopia (71.0\%) (Belayneh et al., 2015). However, it was higher than the results obtained among 1,510 TB/HIV co-infection in Kelantan between 2003 to 2012 (27.9\%) (Jalal et al., 2017), the Southern Region of Ethiopia (29.0\%) (Fiseha et al., 2015), Nigeria (48.8\%) (Ofoegbu \& Odume, 2015) and the Eastern Region of Ghana (50.0\%) (Ansa et al., 2012). It was also higher than reports from Ethiopia, from $6.3 \%$ to $20.0 \%$ (WHO, 2006; Ministry of Health Ethiopia, 2013).

According to the WHO Global Tuberculosis Report, the global treatment success rate for TB/HIV patients was $78.0 \%$ (WHO, 2017). The poor success rate observed in this study may be due to the high treatment default and death rates. In addition, the varying success rate between our findings and the results of other findings may be due to the difference in study design, characteristics and number of study participants involved in the study.

In this study, statistically significant differences between categories in TB treatment outcomes (unsuccessful and successful) were observed at the educational level. Treatment outcomes were mainly from individuals with a secondary educational level of more than $77 \%$ for both groups, $84.2 \%$ (241 out of 286 ) in the successful and $77.2 \%$ (294 out of 381 ) in the unsuccessful group. Another study found that lower levels of education were associated with unsuccessful treatment outcomes and mortality (Tok et al., 2020).

In comparison, pulmonary TB anatomy comprised most cases, $58.7 \%$ (168 out of 286) in the unsuccessful and $68.2 \%$ (260 out of 381) in the successful group. It contradicted the study done by others among TB patients (Fekadu et al., 2020; Tok et al., 2020). The presentations with pulmonary $\mathrm{TB}$ were often late resulting in poor treatment outcomes and increased risk of delay to start the treatment. 
For smoking status, most cases were more than $60 \%, 72.0 \%$ (206 of 286) in the unsuccessful and 61.4\% (234 of 381) in the successful group. Tok et al. (2020) found that smoking was associated with unsuccessful treatment outcomes. In this study, the nature of data collection for smoking was self-reporting by patients. Thus, it may have affected these findings. Smoking cessation efforts should be included in standard practice guidelines for TB case management.

In this study, the majority of respondents were under DOTS by health care providers for both groups. However, the cases were extremely higher under DOTS (99.7\%) in the successful groups due to the full support and commitment from healthcare workers and patients. It is hoped that the DOTS would improve the cure rate in the future.

The notification source also showed a significant difference between the unsuccessful and successful groups, more than $76.6 \%$ reported from public hospitals than the public health clinics in both groups. It may be due to the diagnosis of TB cases were diagnosed entirely in the public hospital rather than the health clinic. In future, we also propose to engage all relevant stakeholders to notify the TB cases in line with the law in Malaysia, under Act 342: Prevention and Control of Infectious Diseases.

In terms of the place of treatment, most cases received the treatment in the public hospital for both groups. Only a few cases received treatment from the private health sector, $2(0.7 \%)$ cases in the unsuccessful group and only $1(0.3 \%)$ case in the successful group. This study finding is lower than reported in all patients registered in the 2012 Malaysian National TB Surveillance Database, 6.7\% (Liew et al., 2015). The alternative to receiving the treatment in the private sector is not too much due to socio-economic factors. They need to pay a high cost of treatment in the private health sector. These observations are essential as the place of treatment affecting the outcomes of TB treatment.

In this study, the number of passive detection was higher in the unsuccessful and the successful group, $87.8 \%$ and $83.7 \%$, respectively. The passive detection of TB cases was also identified as the factor associated with all-cause mortality among TB patients in Malaysia from 2014 to 2017 (Tok et al., 2020). Currently, the National Strategic Plan (NSP) for TB Control in Malaysia (2016 to 2020) had planned the strategic interventions to improve TB treatment outcomes, including efforts to enhance TB case detection. These efforts are ongoing to monitor their impact and subsequently plan for the next NSP from 2021 onwards.

Unemployed and other occupations had a higher proportion than government servants, own businesses and prisoners in both treatment groups. For all occupations, including the unemployed, the proportion in the successful group was higher than in the unsuccessful group. However, this was not statistically significant.

The study findings of TB treatment outcome were invariability differs from other studies conducted in other states due to multifactorial aspects such as socio-demography, 
socio-economic, culture, level of knowledge, drugs used and tolerance to side effects. It also may have been influenced by local service provision settings of the TB patients population. Our findings indicate a need for a strategy to improve the treatment outcomes among TB/ HIV co-infected patients with TB in collaborative activities. The basic data of the patient's socio-demographic and the prevalence of treatment outcome in this study can be used as a baseline to develop the further study. They may also contribute to the body of knowledge regarding the treatment outcomes. Healthcare facilities, particularly in Kelantan, could be encouraged to focus on these relevant areas for TB treatment so that a better outcome of TB treatment can be achieved in the future.

Nevertheless, our study had some limitations. The transfer of outpatients were subsequently excluded from our research, leading to a slight bias in our results. Secondary data was another drawback to this analysis. Patients' information was retrieved from the MyTB online system available in the TB/Leprosy Sector. The issue is the missing data (i.e., marital status and monthly income) cannot be minimized. Since their records were not available and their medical results were ambiguous, these variables could be included. It is hoped that future efforts to start capturing those variables could be made routinely.

\section{CONCLUSION}

This study provided the basic data of the patient's socio-demographic. The prevalence of the TB treatment success rate was $57.1 \%$, which was under the international target by WHO of $\geq 90.0 \%$. However, a high percentage of TB patients have died. It is a major public health issue that urgently needs to be resolved. It is essential to know the associated factors related to successful treatment. Further studies should be carried out, and intervention studies should be organised once the associated factors have been identified.

\section{ACKNOWLEDGMENT}

The authors wish to thank the Director-General of Health, Malaysia, for his kind permission to publish these research findings. Furthermore, our heartfelt thanks are extended to patients whose data were involved in this study.

\section{REFERENCES}

Abrha, H., Tsehayneh, B., Massa, D., Tesfay, A., \& Kahsay, H. (2015). Survival experience and its predictors among TB/HIV co-infected patients in Southwest Ethiopia. Epidemiology (Sunnyvale), 5(3), 3-9. https:// doi.org/10.4172/2161-1165.1000191

Adejumo, O. A., Daniel, O. J., Otesanya, A. F., Adegbola, A. A., Femi-Adebayo, T., Bowale, A., Adesola, S., Kuku, O. O., Otemuyiwa, K. O., Oladega, S. N., Johnson, E. O., Falana, A. A., Dawodu, O., Owuna, H., Osoba, G., \& Dacosta, A. (2017). Factors associated with TB/HIV co-infection among drug sensitive 
tuberculosis patients managed in a secondary health facility in Lagos, Nigeria. African Journal of Infectious Diseases, 11(2), 75-82. https://doi.org/10.21010/ajid.v11i2.10

Ali, S. A., Mavundla, T. R., Fantu, R., \& Awoke, T. (2016). Outcomes of TB treatment in HIV co-infected TB patients in Ethiopia: A cross-sectional analytic study. BMC Infectious Diseases, 16(1), Article 640. https://doi.org/10.1186/s12879-016-1967-3

Ansa, G. A., Walley, J. D., Siddiqi, K., \& Wei, X. (2012). Assessing the impact of TB/HIV services integration on TB treatment outcomes and their relevance in TB/HIV monitoring in Ghana. Infectious Diseases of Poverty, 1(1), 1-8. https://doi.org/10.1186/2049-9957-1-13

Belayneh, M., Giday, K., \& Lemma, H. (2015). Treatment outcome of Human Immunodeficiency Virus and Tuberculosis co-infected patients in public hospitals of eastern and southern zone of Tigray Region, Ethiopia. Brazilian Journal of Infectious Diseases, 19(1), 47-51. https://doi.org/10.1016/j.bjid.2014.09.002

Duru, C. B., Uwakwe, K. A., Nnebue, C. C., Diwe, K. C., Merenu, I. A., Emerole, C. O., Iwu, C. A., \& Duru, C. A. (2016). Tuberculosis treatment outcomes and determinants among patients treated in hospitals in Imo State, Nigeria. OALib, 03(06), 1-17. https://doi.org/10.4236/oalib.1102754

Eyasu, E., Tadesse, B., \& Tsedeke, W. (2014). Tuberculosis treatment outcomes among Tuberculosis/Human Immunodeficiency co-infected cases treated under directly observed treatment of short course in western Ethiopia. Journal of AIDS and HIV Research, 6(8), 164-171. https://doi.org/10.5897/jahr2014.0312

Fekadu, G., Turi, E., Kasu, T., \& Bekele, F. (2020). Impact of HIV status and predictors of successful treatment outcomes among Tuberculosis patients : A six-year retrospective cohort study. Annals of Medicine and Surgery, 60, 531-541. https://doi.org/10.1016/j.amsu.2020.11.032

Fiseha, T., Gebru, T., Gutema, H., \& Debela, Y. (2015). Tuberculosis treatment outcome among HIV coinfected patients at Mizan-Aman General Hospital, Southwest Ethiopia: A retrospective study fiseha. Bioengineering \& Biomedical Science, 5(1), 1-4. https://doi.org/10.4172/2155-9538.1000139

Hannah, H. A., Miramontes, R., \& Gandhi, N. R. (2017). Sociodemographic and clinical risk factors associated with Tuberculosis mortality in the United States, 2009-2013. Public Health Reports, 132(3), 366-375. https://doi.org/10.1177/0033354917698117

Ismail, I., \& Bulgiba, A. (2013). Determinants of unsuccessful Tuberculosis treatment outcomes in Malaysian HIV-infected patients. Preventive Medicine, 57(SUPPL), S27-S30. https://doi.org/10.1016/j. ypmed.2012.12.023

Jacobson, K. B., Moll, A. P., Friedland, G. H., \& Shenoi, S. V. (2015). Successful Tuberculosis treatment outcomes among HIV/TB coinfected patients down-referred from a district hospital to primary health clinics in rural South Africa. PLoS ONE, 10(5), 1-11. https://doi.org/10.1371/journal.pone.0127024

Jalal, T. M. T., Abdullah, S., Wahab, F. A., Dir, S., \& Naing, N. N. (2017). Prevalence and factors associated with Tuberculosis treatment success among TB/ HIV co-infection in north-east Malaysia. Malaysian Journal of Medical Sciences, 24(6), 75-82. https://doi.org/10.21315/mjms2017.24.6.9

Liew, S. M., Khoo, E. M., Ho, B. K., Lee, Y. K., Mimi, O., Fazlina, M. Y., Asmah, R., Lee, W. K., Harmy, M. Y., Chinna, K., \& Jiloris, F. D. (2015). Tuberculosis in Malaysia: Predictors of treatment outcomes in a national registry. International Journal of Tuberculosis and Lung Disease, 19(7), 764-771. https://doi. org/10.5588/ijtld.14.0767 
Liu, Y., Zheng, Y., Chen, J., Shi, Y., Shan, L. Y., Wang, S., Wang, W. B., Shen, X., \& Zhang, Y. (2018). Tuberculosis-associated mortality and its risk factors in a district of Shanghai, China: A retrospective cohort study. International Journal of Tuberculosis and Lung Disease, 22(6), 655-660. https://doi. org/10.5588/ijtld.17.0726

Mekonnen, D., Derbie, A., \& Desalegn, E. (2015). TB/HIV co-infections and associated factors among patients on directly observed treatment short course in Northeastern Ethiopia: A 4 years retrospective study. BMC Research Notes, 8(1), 1-6. https://doi.org/10.1186/s13104-015-1664-0

Ministry of Health. (2015). Global AIDS response progress report Malaysia 2015. In Ministry of Health (Issue March).

Ministry of Health Ethiopia. (2013). National TB/HIV sentinel surveillance one year report (July 2011 - June 2012). Ministry of Health Ethiopia.

Ministry of Health Malaysia. (2012). Clinical practice guidelines: Management of Tuberculosis (3rd Ed.). Ministry of Health Malaysia.

Ministry of Health Malaysia. (2016). Clinical practice guidelines: Management of drug-resistant Tuberculosis (1st Ed.). Ministry of Health Malaysia.

Ofoegbu, O. S., \& Odume, B. B. (2015). Tuberculosis patients at National Hospital Abuja Nigeria: A five year retrospective study. South African Family Practice, 57(1), 50-56. https://doi.org/10.1080/2078619 0.2014 .995913

Oshi, D. C., Oshi, S. N., Alobu, I., \& Ukwaja, K. N. (2014). Profile, outcomes, and determinants of unsuccessful Tuberculosis treatment outcomes among HIV-infected Tuberculosis patients in a Nigerian State. Tuberculosis Research and Treatment, 2014, 1-8. https://doi.org/10.1155/2014/202983

Ronaidi, N. M. N. N., Mohd, N. S., Mohammad, W. Z., Sharina, D., \& Rosmawati, N. H. N (2011). Factors associated with unsuccessful treatment outcome of Pulmonary Tuberculosis in Kota Bharu, Kelantan. Malaysian Journal of Public Health Medicine, 11(1), 6-15.

Sinshaw, Y., Alemu, S., Fekadu, A., \& Gizachew, M. (2017). Successful TB treatment outcome and its associated factors among TB/HIV co-infected patients attending Gondar University Referral Hospital, Northwest Ethiopia: An institution based cross-sectional study. BMC Infectious Diseases, 17, 1-9. https:// doi.org/10.1186/s12879-017-2238-7

Tok, P. S. K., Liew, S. M., Wong, L. P., Razali, A., Loganathan, T., Chinna, K., Ismail, N., \& Kadir, N. A. (2020). Determinants of unsuccessful treatment outcomes and mortality among Tuberculosis patients in Malaysia: A registry-based cohort study. PLOS ONE, 15(4), 1-14. https://doi.org/10.1371/journal.pone.0231986

Tweya, H., Feldacker, C., Phiri, S., Ben-Smith, A., Fenner, L., Jahn, A., Kalulu, M., Weigel, R., Kamba, C., Banda, R., Egger, M., \& Keiser, O. (2013). Comparison of treatment outcomes of new smear-positive Pulmonary Tuberculosis patients by HIV and antiretroviral status in a TB/HIV Clinic, Malawi. PLoS ONE, 8(2), Article e56248. https://doi.org/10.1371/journal.pone.0056248

Warkari, P. D., Nakel, M. P., Mahajan, S. M., \& Adchitre, S. A. (2017). Study of treatment outcome of Tuberculosis among HIV co-infected patients: A cross sectional study in Aurangabad City, Maharashtra. International Journal Of Community Medicine And Public Health, 4(12), 4466-4471. https://doi. org/10.18203/2394-6040.ijcmph20175163 
Wen, Yufeng, Zhang, Zhiping, Li, Xianxiang, Xia, Dan, Jun, M., Dong, Y., \& Zhang, X. (2018). Treatment outcomes and factors affecting unsuccessful outcome among new Pulmonary smear positive and negative Tuberculosis patients in Anqing, China: A retrospective study. BMC Infectious Diseases, 18(104), 1-12. https://doi.org/https://doi.org/10.1186/s12879-018-3019-7

WHO. (2006). The stop TB strategy. World Health Organization.

WHO. (2008). A revised framework to address TB-HIV co-infection in the Western Pacific Region. World Health Organization.

WHO. (2017). Global Tuberculosis report 2017. World Health Organization.

WHO. (2018a). Global Tuberculosis report 2018. World Health Organization.

WHO. (2018b). TB-HIV factsheet 2018. World Health Organization.

WHO. (2019). Global Tuberculosis report 2019: Executive summary. World Health Organization. 
